\title{
The Value of Fractional Exhaled Nitric Oxide and Impulse Oscillometric and Spirometric Parameters for Predicting Bronchial Hyperresponsiveness in Adults with Chronic Cough
}

\author{
Lichang Chen ${ }^{1, *}$ \\ Lingling $\mathrm{Wu}^{\mathrm{l}, *}$ \\ Dongzhu Lu (D) \\ Mei $\mathrm{Zi}^{2}$ \\ Huapeng $\mathrm{Yu}^{\prime}$ \\ 'Department of Respiratory Medicine, \\ Zhujiang Hospital, Southern Medical \\ University, Guangzhou, People's Republic \\ of China; ${ }^{2}$ Department of Respiratory \\ and Critical Care Medicine, The Third \\ People's Hospital of Shenzhen, Shenzhen, \\ People's Republic of China
}

*These authors contributed equally to this work
Correspondence: Huapeng Yu

Department of Respiratory Medicine,

Zhujiang Hospital, Southern Medical

University, Guangzhou, 5I 0220, People's

Republic of China

Tel +8602061643175

Fax +8602084306143

Email huapengyu@aliyun.com
Purpose: To evaluate the contribution of fractional exhaled nitric oxide (FeNO) and impulse oscillometry (IOS) and spirometric parameters in predicting bronchial hyperresponsiveness (BHR) in adults with chronic cough.

Patients and Methods: In total, 112 patients with chronic cough were enrolled in this prospective diagnostic study. Receiver operating characteristic (ROC) curves were generated to assess the diagnostic efficiency and optimal cut-off values of FeNO and IOS and spirometric parameters in predicting BHR. Optimal combinations of FeNO and IOS and spirometric parameters for BHR prediction were investigated using univariate and multivariate logistic regression models. Bootstrapping was employed for internal validation. Model discrimination and calibration were assessed using indices and calibration plots.

Results: Rhinitis and values of FeNO, IOS parameters (resonant frequency (Fres), reactance at $5 \mathrm{~Hz}(\mathrm{X} 5)$, and integrated area of low-frequency $\mathrm{X}(\mathrm{AX})$ ) and spirometric parameters (FEV1, PEF, $\mathrm{MEF}_{75}, \mathrm{MEF}_{50}, \mathrm{MEF}_{25}, \mathrm{MMEF}$ ) were significantly different between patients with BHR and those without BHR $(\mathrm{P}<0.05)$. After adjusting for rhinitis, logistic analyses showed that FeNO combined with Fres, FeNO combined with MMEF, or the combination of FeNO, Fres and MMEF had high predictive value in diagnosing BHR; the areas under the ROC curves (AUCs) of the corresponding three models were 0.914, 0.919 and 0.927, respectively. In addition, the three models displayed good discrimination, with high $\mathrm{C}$-index values and good calibration.

Conclusion: FeNO combined with Fres or MMEF or a combination of these three parameters may be conveniently used as indicators in BHR prediction.

Keywords: maximum mid-expiratory flow, resonant frequency, cough variant asthma, ROC curve, diagnosis

\section{Introduction}

Cough is not only a physiological reflex that protects the lower airways against aspiration but also one of the most common conditions for which patients seek medical attention. ${ }^{1,2}$ Cough can be classified into three categories according to the duration of symptoms: acute cough ( $<3$ weeks), subacute cough ( 3 to 8 weeks) and chronic cough $\left(>8\right.$ weeks). ${ }^{3}$ Coughvariant asthma (CVA), the most common pathogenesis of chronic cough, is characterized by cough as the predominant symptom and bronchial hyperresponsiveness (BHR). ${ }^{4,5}$ BHR is usually detected by a positive bronchial provocation test (BPT) or a positive 
reaction to bronchodilators. ${ }^{6,7}$ However, the BPT requires patients to perform consistent, maximal forced-exhalation manoeuvres with coaching and repeated attempts to satisfy standards for repeatability and reproducibility; thus, it is expensive and time consuming, and it may cause severe bronchospasm. ${ }^{8}$ Therefore, simpler, safer, or less expensive tests, individually or in combination, that can be performed in primary hospitals without the BPT are needed.

The measurement of fractional exhaled nitric oxide (FeNO) is a non-traumatic, convenient, rapid and safe means of assessing airway inflammation, ${ }^{9}$ and FeNO can predict BHR in patients with suspected asthma or chronic cough. ${ }^{10-12}$ In addition, recent studies have shown that patients with BHR in the chronic cough population have small airway dysfunction (SAD) and that small-airway function parameters may be used to predict BHR in this population. ${ }^{12}$ Therefore, FeNO and small-airway function parameters might be used as markers of CVA in patients with chronic cough. Many techniques are currently available for the evaluation of small airways, such as spirometry, body plethysmography, impulse oscillometry (IOS), breath nitrogen washout and high-resolution CT (HRCT). ${ }^{13-16}$ Forced expiratory flow (FEF) between 25\% and $75 \%\left(\mathrm{FEF}_{25 \%-75 \%}\right)$, also known as maximum midexpiratory flow (MMEF), measured with a spirometer can reflect small-airway function, especially in subjects with normal values of forced expiratory volume in 1 $\mathrm{s}$ (FEV1) and $\mathrm{FEV} 1 /$ forced vital capacity (FVC). ${ }^{17}$ Unlike spirometry, which measures the volume displacement of air through forceful expiratory and inspiratory manoeuvres, IOS does not require any effort from the subject. ${ }^{18}$ Importantly, IOS distinguishes SAD from large airway obstruction and is more sensitive than spirometry in detecting peripheral airway diseases. ${ }^{15,18}$

A retrospective study found that $\mathrm{FeNO}$ and $\mathrm{FEF}_{25 \%-75 \%}$ can predict $\mathrm{BHR}$ in adults with chronic cough. ${ }^{12}$ However, no prospective study of the value of IOS and FeNO for predicting BHR in adults with chronic cough has been performed to date. The purpose of this study was to evaluate the diagnostic value of FeNO and IOS and spirometric parameters for predicting BHR in patients with chronic cough.

\section{Patients and Methods}

\section{Study Design and Subject Selection}

From August 2018 to February 2019, patients at Zhujiang Hospital of Southern Medical University who met all of the following inclusion criteria were consecutively enrolled in this prospective diagnostic study: (1) age 1875 years; (2) cough as the sole symptom lasting for at least 8 weeks, no fever or blood-stained sputum, and no wheezing or shortness of breath ever; (3) no radiographic evidence of lung disease; (4) no history of asthma or other lung disease, such as bronchiolitis obliterans, bronchiectasis, or cystic fibrosis; and (5) non-smokers or ex-smokers who had abstained from smoking for at least 6 months prior to the study. The exclusion criteria were as follows: (1) use of inhaled or oral corticosteroids in the previous 4 weeks or montelukast and long-acting b2-agonists in the previous week; (2) percent predicted FEV1 less than 70\%; and (3) pregnancy. All subjects provided informed consent before inclusion. The demographic information of the participants was collected, including history of rhinitis and rhinosinusitis. If there was no history of rhinitis or sinusitis but the subject had nasal symptoms such as nasal congestion and runny nose, the patient was evaluated by an otolaryngologist for rhinitis and sinusitis. FeNO measurement, IOS, spirometry and the BPT were performed by the same researcher.

\section{$\mathrm{FeNO}$}

FeNO measurements were obtained using a NIOX MINO portable instrument (Aerocrine, Sweden) at a constant flow rate of $50 \mathrm{~mL} / \mathrm{s}$ and in accordance with ATS/ERS recommendations. ${ }^{19}$

\section{IOS}

IOS was carried out using the MasterScreen IOS-Jaeger device (Germany) according to the manufacturer's recommendations. ${ }^{20}$ The following values were obtained: impedance at $5 \mathrm{~Hz}(\mathrm{Z} 5)$, resistance at $5 \mathrm{~Hz}$ (R5), resistance at $20 \mathrm{~Hz}$ (R20), the difference between R5 and R20 (R5$\mathrm{R} 20$ ), reactance at $5 \mathrm{~Hz}$ (X5), resonant frequency (Fres), and integrated area of low-frequency $\mathrm{X}(\mathrm{AX})$ values.

\section{Spirometry and the Methacholine Challenge Test}

Spirometry was conducted using the Jaeger MasterScreen device (Jaeger GmbH, Wurzburg, Germany) according to the recommendations of the American Thoracic Society (ATS)/European Respiratory Society (ERS). ${ }^{21}$ The methacholine provocation test (MPT), one of the most common BPTs, was performed with the Jaeger APS Pro system with doubling methacholine doses $(0.0725-0.48 \mathrm{mg})$ 


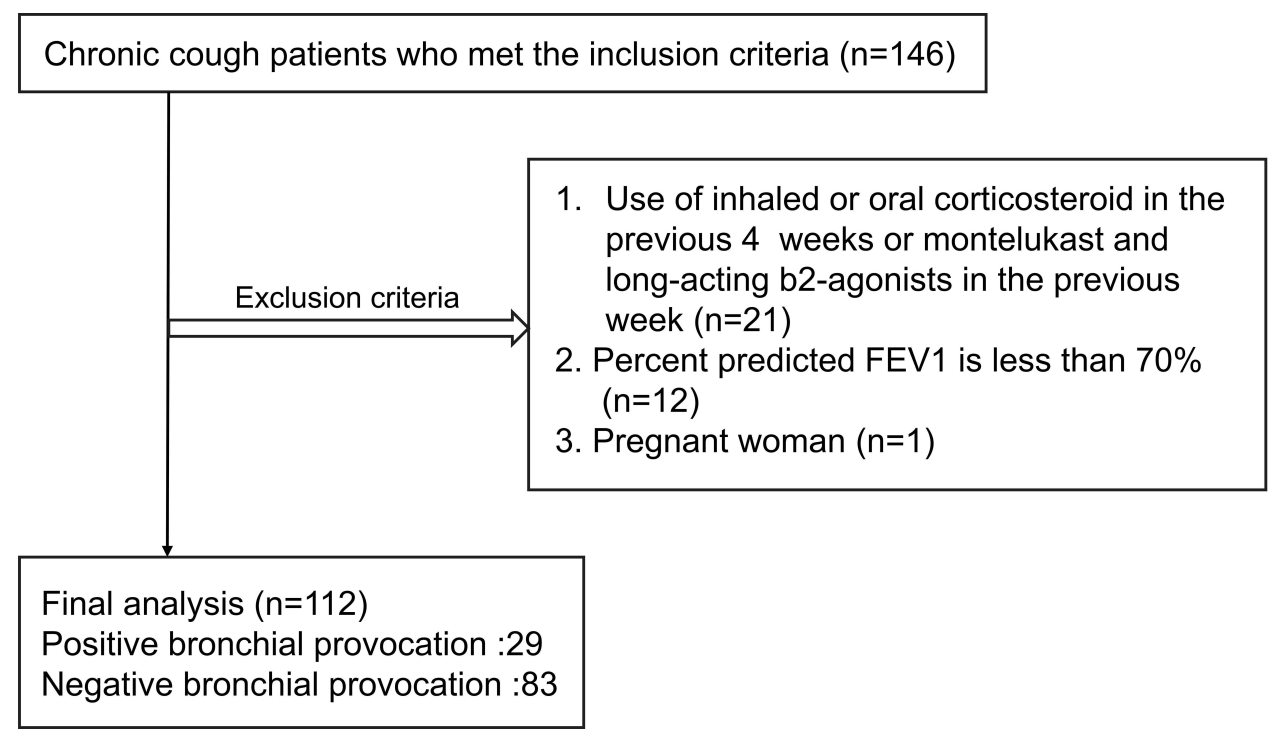

Figure I Enrollment flow chart of the study.

following ATS/ERS guidelines. BHR was defined as the provocative dose inducing a $20 \%$ decrease in FEV1 $\left(\mathrm{PD}_{20}\right.$ FEV1) $\leq 2.5$ mg. $^{8}$

\section{Statistical Analysis}

Statistical analyses were performed using IBM SPSS Statistics (version 19.0), GraphPad Prism (version 7.0), and $\mathrm{R}$ software (version 4.1.0). $\mathrm{P}$ values were two-sided, and $P$ values less than 0.05 were considered statistically significant. The normality of the distribution of each continuous variable was examined using the Kolmogorov-Smirnov method. Normally distributed variables are described as the mean (SD); nonnormally distributed variables are described as the median (range). Comparisons of parameters between patients with BHR and those without were performed using the independent sample $t$-test or Mann-Whitney $U$-test depending on data normality. Enumeration variables were expressed as numbers (percentages) and were analysed using the chi-square test. Receiver operating characteristic (ROC) curves and the areas under the ROC curves (AUCs) were used to determine the diagnostic value and best cut-off value for each parameter (with the best cut-off value corresponding to the maximum value of the Youden index). Univariate logistic regression analysis was performed to explore pathological BHR-related variables. Statistically significant parameters $(\mathrm{P}<0.05)$ in univariate logistic regression analyses were included in subsequent multivariate analyses. Multivariate logistic regression analysis (method: backward LR) was applied to identify variables that are independent influencing factors of BHR and to establish prediction models. AUCs were used again to determine the diagnostic value and the best cut-off value for the prediction models. We then established control models using 1000 bootstrapped samples and calculated the relatively corrected C-index in $\mathrm{R}$ software. A calibration curve was generated in $\mathrm{R}$ software to verify the consistency of each model.

\section{Results \\ Patient Characteristics}

A total of 112 patients met the criteria of this study: 29 (25.9\%) and $93(74.1 \%)$ were confirmed to have positive and negative bronchial provocation, respectively (Figure 1). The presence of allergic rhinitis $(\mathrm{P}=0.001)$ was significantly different between patients with BHR and those without, but there was no significant difference in the other demographic variables between the two groups (Table 1). The values of FeNO $(\mathrm{P}<0.001)$, Fres $(\mathrm{P}=0.005), \mathrm{X} 5 \quad(\mathrm{P}=0.001), \mathrm{AX}$ $(\mathrm{P}=0.010), \quad$ FEV1 $\quad(\mathrm{P}=0.021), \quad \mathrm{PEF} \quad(\mathrm{P}=0.002), \quad \mathrm{MEF}_{75}$ $(\mathrm{P}<0.001), \quad \mathrm{MEF}_{50} \quad(\mathrm{P}<0.001), \quad \mathrm{MEF}_{25} \quad(\mathrm{P}=0.034) \quad$ and MMEF $(\mathrm{P}<0.001)$ showed significant differences between patients with BHR and those without BHR (Table 2).

\section{Diagnostic Accuracy of Parameters for BHR Prediction}

The ROC analysis showed that FeNO (AUC 0.854, $\mathrm{P}<0.001$ ), Fres (AUC 0.649, $\mathrm{P}=0.017$ ), X5 (AUC 0.701, $\mathrm{P}=0.001$ ), AX (AUC 0.661, $\mathrm{P}=0.010$ ), FEV1 (AUC 0.632, $\mathrm{P}=0.035), \mathrm{PEF}(\mathrm{AUC} 0.674, \mathrm{P}=0.005), \mathrm{MEF}_{75}(\mathrm{AUC} 0.714$, $\mathrm{P}<0.001), \mathrm{MEF}_{50}(\mathrm{AUC} 0.725, \mathrm{P}<0.001), \mathrm{MEF}_{25}$ (AUC 
Table I Demographics of the Patients with Positive or Negative Bronchial Provocation Tests

\begin{tabular}{|l|l|l|l|}
\hline Demographics & $\begin{array}{l}\text { Positive Bronchial } \\
\text { Provocation (n=29) }\end{array}$ & $\begin{array}{l}\text { Negative Bronchial } \\
\text { Provocation (n=83) }\end{array}$ & $\mathbf{p}$ \\
\hline Age (year) & $36.55(12.10)$ & $39.87(11.42)$ & 0.188 \\
Male/female (n) & $11 / 18$ & $39 / 44$ & 0.398 \\
Height (cm) & $160.07(8.23)$ & $162.35(8.34)$ & 0.206 \\
Weight (kg) & $56.83(9.8 I)$ & $61.43(12.4 I)$ & 0.074 \\
Symptom duration (month) & $6(2-36)$ & $4(2-96)$ & 0.670 \\
Never smoker/Ex-smoker & $23 / 6$ & $72 / 11$ & 0.372 \\
Rhinitis (n [\%]) & $14[48.3]$ & $15[18.1]$ & $0.001 *$ \\
Rhinosinusitis (n [\%]) & $0[0.00]$ & $2[0.02]$ & - \\
History of GRED or gastrointestinal symptoms such as & $3[0.103]$ & $6[0.072]$ & 0.693 \\
heartburn and dyspepsia & & & \\
\hline
\end{tabular}

Notes: Data are expressed as mean (SD) or median (range), unless indicated otherwise. *Statistical significance.

Abbreviation: GRED, gastroesophageal reflux disease.

0.629, $\mathrm{P}=040$ ) and MMEF (AUC 0.726, $\mathrm{P}<0.001$ ) had positive effects in predicting BHR (Figure $2 \mathrm{~A}$ and $\mathrm{B}$ ). The optimal cut-off values for each parameter were as follows: FeNO, 31.5 ppb (sensitivity, 65.52\%; specificity, 93.98\%); Fres, $13.33 \mathrm{~Hz}$ (sensitivity, 62.07\%; specificity, 68.67\%); X5,
$-0.095 \mathrm{kPa} / \mathrm{L} / \mathrm{s}$ (sensitivity, $82.76 \%$; specificity, 49.4\%); AX, $0.395 \mathrm{kPa} / \mathrm{L}$ (sensitivity, 58.62\%; specificity, 67.47\%); FEV1, 90.85 (sensitivity, 44.38\%; specificity, 80.72\%); PEF, 82.2 (sensitivity, 48.28\%; specificity, 79.52\%); $\mathrm{MEF}_{75}, 78.05$ (sensitivity, 48.28\%; specificity, 86.75\%);

Table 2 Parameters of the Patients with Positive or Negative Bronchial Provocation Tests

\begin{tabular}{|c|c|c|c|}
\hline Parameters & Positive Bronchial Provocation $(n=29)$ & Negative Bronchial Provocation $(n=83)$ & $\mathbf{p}$ \\
\hline $\mathrm{FeNO}(\mathrm{ppb})$ & $43(5-97)$ & $10(5-48)$ & $<0.001 *$ \\
\hline \multicolumn{4}{|l|}{ IOS } \\
\hline $\mathrm{Z5}\left(\mathrm{kpa} \cdot \mathrm{L}^{-1} \cdot \mathrm{s}^{-1}\right)$ & $0.44(0.12)$ & $0.4 \mathrm{I}(0.97)$ & 0.091 \\
\hline Fres $(\mathrm{Hz})$ & $14.45(4.25)$ & $12.32(3.17)$ & $0.005^{*}$ \\
\hline R5 $\left(\mathrm{kpa} \cdot \mathrm{L}^{-1} \cdot \mathrm{s}^{-1}\right)$ & $0.42(0.11)$ & $0.39(0.10)$ & 0.169 \\
\hline $\mathrm{R} 20\left(\mathrm{kpa} \cdot \mathrm{L}^{-1} \cdot \mathrm{s}^{-1}\right)$ & $0.34(0.20-0.49)$ & $0.32(0.23-0.62)$ & 0.400 \\
\hline R5-R20 (kpa $\left.\mathrm{L}^{-1} \cdot \mathrm{s}^{-1}\right)$ & $0.06(0.00-0.19)$ & $0.04(0.00-0.22)$ & 0.109 \\
\hline X5 $\left(\mathrm{kpa} \cdot \mathrm{L}^{-1} \cdot \mathrm{s}^{-1}\right)$ & $-0.13(0.05)$ & $-0.10(0.04)$ & $0.00 I^{*}$ \\
\hline AX & $0.44(0.13-2.22)$ & $0.30(0.02-1.5 I)$ & $0.010^{*}$ \\
\hline \multicolumn{4}{|l|}{ Spirometry } \\
\hline FVC (\% predicted) & $99.79(13.30)$ & $102.4 \mid(13.40)$ & 0.365 \\
\hline FEVI (\% predicted) & $94.05(11.09)$ & $100.17(12.46)$ & $0.021^{*}$ \\
\hline FEVI/FVC (\% predicted) & $80.33(6.26)$ & 82.69 (5.99) & 0.074 \\
\hline PEF (\% predicted) & $82.32(15.07)$ & $92.77(15.68)$ & $0.002^{*}$ \\
\hline $\mathrm{MEF}_{75}$ (\% predicted) & $83.5 I(I 5.08)$ & $97.34(I 7.8 I)$ & $<0.001 *$ \\
\hline $\mathrm{MEF}_{50}(\%$ predicted $)$ & $74.54(16.62)$ & $92.93(23.69)$ & $<0.001 *$ \\
\hline $\mathrm{MEF}_{25}$ (\% predicted) & $63.04(21.40)$ & $75.38(28.30)$ & $0.034^{*}$ \\
\hline MMEF (\% predicted) & $67.21(16.49)$ & $83.47(20.85)$ & $<0.001 *$ \\
\hline
\end{tabular}

Notes: Data are expressed as mean (SD) or median (range), unless indicated otherwise. *Statistical significance.

Abbreviations: FeNO, fractional exhaled nitric oxide; ppb, parts per billion; IOS, impulse oscillometry; Z5, impedance at $5 \mathrm{~Hz}$; Fres, resonant frequency; R5, resistance at 5 $\mathrm{Hz}$; R20, resistance at $20 \mathrm{~Hz}$; R5-R20, the difference between R5 and R20; X5, reactance at $5 \mathrm{~Hz}$; AX, integrated area of low-frequency X; FVC, forced vital capacity; FEVI, forced expiratory volume in Is; PEF, peak expiratory flow; $\mathrm{MEF}_{75}$, forced expiratory flow at $75 \%$ of the FVC; $\mathrm{MEF}_{50}$, forced expiratory flow at $50 \%$ of the $\mathrm{FVC}$; $\mathrm{MEF}_{25}$, forced expiratory flow at $25 \%$ of the FVC; MMEF, forced expiratory flow between 25 and $75 \%$. 
A

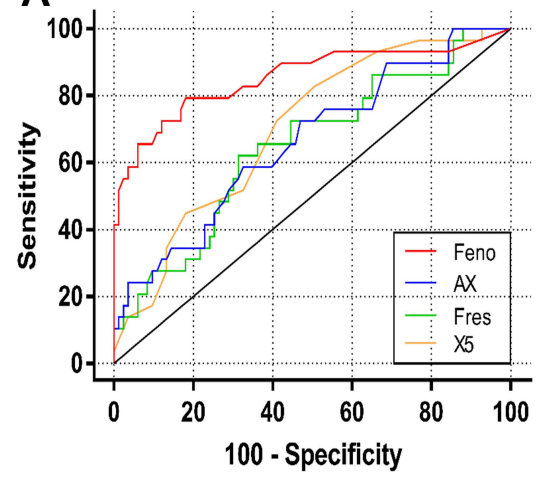

B

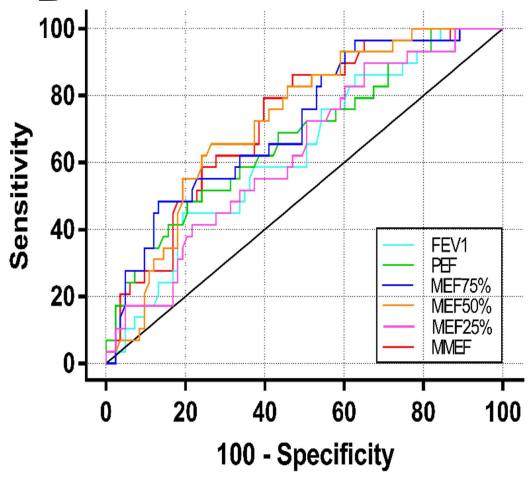

C

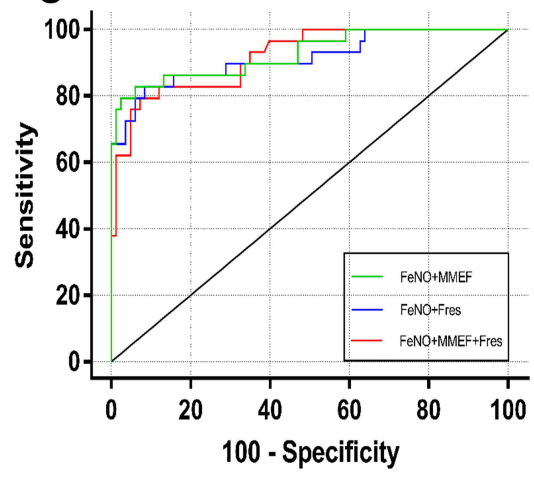

Figure 2 ROC curves of (A) FeNO and IOS parameters, (B) spirometric parameters and (C) FeNO combined with Fres, FeNO combined with MMEF, or a combination of FeNO, Fres and MMEF in predicting a positive bronchial provocation test.

$\mathrm{MEF}_{50}, 76.95$ (sensitivity, 65.52\%; specificity, 73.49\%); $\mathrm{MEF}_{25}, 81.25$ (sensitivity, 89.66\%; specificity, 34.94); and MMEF, 77.50 (sensitivity, 79.31\%; specificity, 60.24\%).

\section{Univariate and Multivariate Logistic Regression Models}

According to the univariate logistic analyses, allergic rhinitis $(\mathrm{P}=0.001)$, FeNO $(\mathrm{P}<0.001)$, Fres $(\mathrm{P}=0.005), \mathrm{X} 5$ $(\mathrm{P}=0.001), \quad \mathrm{AX} \quad(\mathrm{P}=0.010), \quad$ FEV1 $\quad(\mathrm{P}=0.021), \quad \mathrm{PEF}$ $(\mathrm{P}=0.002), \mathrm{MEF}_{75}(\mathrm{P}<0.001), \mathrm{MEF}_{50}(\mathrm{P}<0.001), \mathrm{MEF}_{25}$ $(\mathrm{P}=0.034)$ and MMEF $(\mathrm{P}<0.001)$ were associated with BHR (Table 3). Multivariate logistic analysis (Table 4) and ROC curves (Figure 2C) revealed that among FeNO,

Table 3 Univariate Logistic Regression Analyses of Parameters from Chronic Cough to Predict Positive Bronchial Provocation Tests

\begin{tabular}{|c|c|c|c|}
\hline Variable & $\boldsymbol{\beta}$ & OR(95\% CI) & $\mathbf{p}$ \\
\hline $\mathrm{FeNO}$ & 0.097 & I.I02 (I.062-I.I44) & $<0.000$ \\
\hline Allergic rhinitis & -1.442 & $0.236(0.094-0.592)$ & 0.002 \\
\hline Fres & 0.163 & I.I 77 (I.043-I.328) & 0.008 \\
\hline X5 & -19.202 & $0.000(0.000-0.002)$ & 0.003 \\
\hline$A X$ & 1.709 & $5.525(1.695-18.003)$ & 0.005 \\
\hline FEVI (\% predicted) & -0.043 & $0.958(0.922-0.994)$ & 0.024 \\
\hline PEF (\% predicted) & -0.046 & $0.955(0.926-0.985)$ & 0.003 \\
\hline $\mathrm{MEF}_{75}$ (\% predicted) & -0.051 & $0.951(0.923-0.979)$ & 0.001 \\
\hline $\mathrm{MEF}_{50}(\%$ predicted) & $-0.04 I$ & $0.960(0.937-0.983)$ & 0.001 \\
\hline $\mathrm{MEF}_{25}$ (\% predicted) & -0.019 & $0.981(0.963-0.999)$ & 0.038 \\
\hline MMEF (\% predicted) & -0.043 & $0.958(0.934-0.982)$ & 0.001 \\
\hline
\end{tabular}

Notes: Method: Enter; Dependent Y: BHR; Enter Variable < 0.05; Remove Variable $>0.1$.

Abbreviations: OR, odds ratio; FeNO, fractional exhaled nitric oxide; ppb, parts per billion; Fres, resonant frequency; $X 5$, reactance at $5 \mathrm{~Hz} ; A X$, integrated area of low-frequency X; FEVI, forced expiratory volume in Is; PEF, peak expiratory flow; $\mathrm{MEF}_{75}$, forced expiratory flow at $75 \%$ of the $\mathrm{FVC}$; $\mathrm{MEF}_{50}$, forced expiratory flow at $50 \%$ of the FVC; $M_{25}$, forced expiratory flow at $25 \%$ of the FVC; MMEF, forced expiratory flow between 25 and $75 \%$. allergic rhinitis and IOS and their combinations, the combination of FeNO and Fres had the strongest predictive performance. The AUC of FeNO combined with Fres was 0.914 (95\% CI, 0.845-0.983; P <0.001), with optimal cutoff values of $37 \mathrm{ppb}$ for FeNO and $10.12 \mathrm{~Hz}$ for Fres (sensitivity, 82.76\%; specificity, 91.57\%). For FeNO,

Table 4 Multivariate Analyses of Characteristics, FeNO, IOS and Spirometric Parameters from Chronic Cough to Predict Positive Bronchial Provocation Tests

\begin{tabular}{|c|c|c|c|}
\hline \multicolumn{4}{|c|}{ Multivariate Analysis of FeNO and Allergic Rhinitis } \\
\hline Variable & $\boldsymbol{\beta}$ & OR(95\% Cl) & $\mathbf{p}$ \\
\hline FeNO & 0.094 & $1.099(1.057-1.142)$ & $<0.001$ \\
\hline \multicolumn{4}{|c|}{ Multivariate analysis of FeNO, Allergic rhinitis and IOS parameters } \\
\hline Variable & $\beta$ & $\mathrm{OR}(95 \% \mathrm{Cl})$ & \\
\hline $\mathrm{FeNO}$ & 0.135 & $1.144(1.084-1.208)$ & $<0.000$ \\
\hline Fres & 0.395 & $1.484(1.191-1.849)$ & 0.000 \\
\hline \multicolumn{4}{|c|}{$\begin{array}{l}\text { Multivariate analysis of FeNO, Allergic rhinitis and Spirometric } \\
\text { parameters }\end{array}$} \\
\hline Variable & $\beta$ & $\mathrm{OR}(95 \% \mathrm{Cl})$ & $P$ \\
\hline $\mathrm{FeNO}$ & 0.109 & $1.115(1.066-1.166)$ & 0.000 \\
\hline MMEF (\% predicted) & -0.057 & $0.945(0.913-0.977)$ & 0.001 \\
\hline \multicolumn{4}{|c|}{$\begin{array}{l}\text { Multivariate analysis of FeNO, Allergic rhinitis and IOS and } \\
\text { Spirometric parameters }\end{array}$} \\
\hline Variable & $\beta$ & $\mathrm{OR}(95 \% \mathrm{Cl})$ & $\mathrm{P}$ \\
\hline FeNO & 0.134 & $1.143(1.080-1.210)$ & 0.000 \\
\hline Fres & 0.331 & $1.393(1.097-1.768)$ & 0.007 \\
\hline MMEF (\% predicted) & -0.044 & $0.957(0.922-0.994)$ & 0.022 \\
\hline
\end{tabular}

Notes: Method: Backward LR; Dependent Y: BHR; Enter Variable $<0.05$; Remove Variable $>0.1$.

Abbreviations: OR, odds ratio; FeNO, fractional exhaled nitric oxide; ppb, parts per billion; Fres, resonant frequency; MMEF, forced expiratory flow between 25 and $75 \%$. 

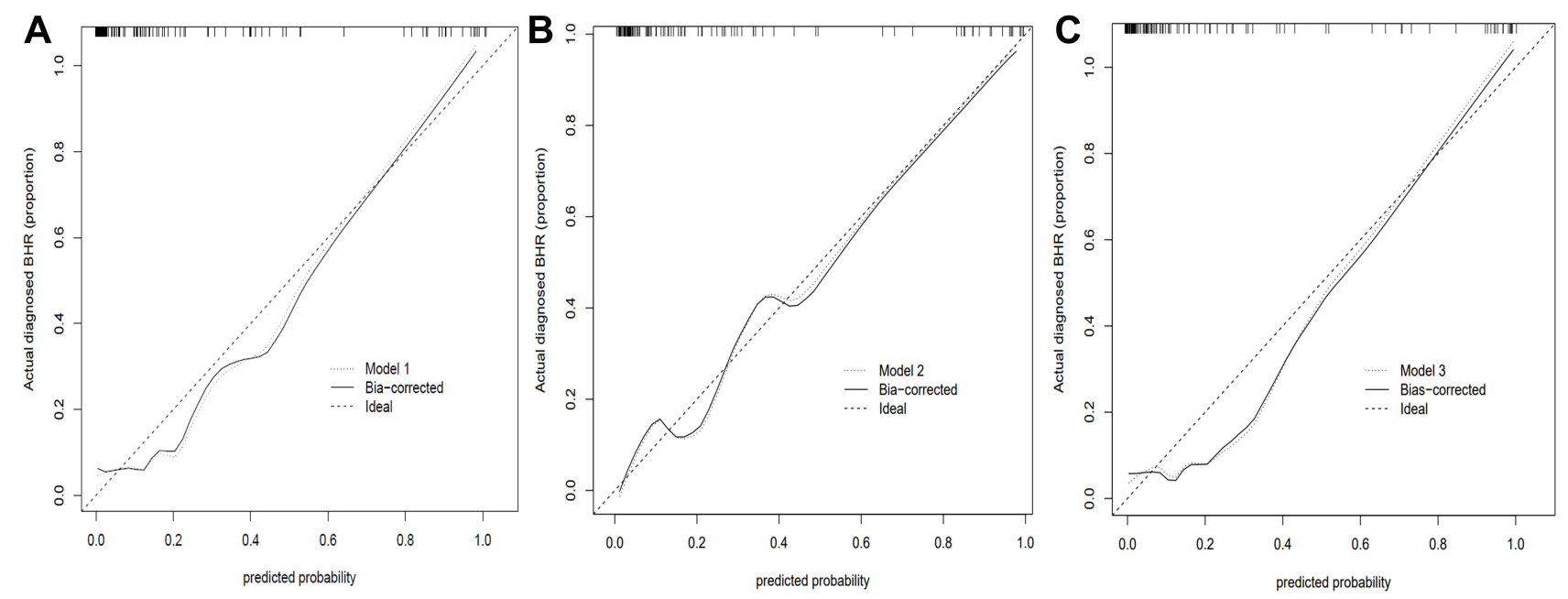

Figure 3 Calibration curves of (A) FeNO combined with Fres (model I), (B) FeNO combined with MMEF (model 2) and (C) the combination of FeNO, Fres, and MMEF (model 3) in predicting a positive bronchial provocation test.

Notes: The $x$-axis represents the predicted risk of BHR. The $y$-axis represents the actual diagnosed BHR. The diagonal dotted line represents a perfect prediction by an ideal model.

allergic rhinitis and spirometric parameters and combinations thereof, the combination of FeNO and MMEF had the strongest predictive value (AUC 0.919; 95\% CI, $0.862-0.976 ; \mathrm{P}<0.001)$. The optimal cut-off values were FeNO $>16$ ppb and MMEF $<53.1 \%$ (sensitivity, 79.31\%; specificity, 92.77\%). Regarding FeNO, allergic rhinitis, IOS and spirometric parameters, multivariate logistic analysis showed that the combination of FeNO, Fres and MMEF had the strongest predictive value (AUC 0.927; 95\% CI, 0.865-0.989; P <0.001); with optimal cut-off values of FeNO $>22 \mathrm{ppb}$, Fres $>15.98 \mathrm{~Hz}$ and MMEF $<60.9 \%$ (sensitivity, $79.31 \%$; specificity, $97.59 \%$ ). The remaining parameters were filtered out due to low predictive value and similarity.

\section{Model Validation}

The calibration curves of the models for predicting BHR in chronic cough patients demonstrated good agreement in this cohort (Figure 3). The C-indices for model 1 (FeNO + Fres), model 2 (FeNO + MMEF) and model 3 (FeNO + Fres + MMEF) were confirmed to be 0.911, 0.914 and 0.921 through bootstrapping validation, suggesting that these models achieve good discrimination.

\section{Discussion}

In this study, we explored the value of FeNO and spirometric and IOS parameters for the diagnosis of BHR in patients with chronic cough. Our study shows that FeNO combined with Fres or MMEF or the combination of these three parameters might be used as a surrogate for BHR in patients with chronic cough.

FeNO is a potential biomarker that reflects airway inflammation, especially eosinophil inflammation, ${ }^{9,21,22}$ and FeNO measurement has an important role in determining the cause of chronic cough. ${ }^{23}$ Introducing FeNO testing in clinical practice for the diagnosis and management of asthma in primary care in Sweden is less costly than standard methods and provides similar health benefits. In a meta-analysis, the reported AUC and $\mathrm{Q}^{*}$ index of the FeNO test for CVA diagnosis were 0.87 and 0.80 , respectively. ${ }^{24}$ Moreover, FeNO $<30$ ppb can help rule out asthma in non-smokers with untreated chronic cough. $^{23}$ Bao et al found that a FeNO value of $43 \mathrm{ppb}$ was the optimal cut-off value for predicting BHR in a Chinese population with chronic cough; the sensitivity, specificity, positive predictive value (PPV) and negative predictive value (NPV) were $71.59 \%, 82.02 \%, 66.30 \%$ and $85.40 \%$, respectively, indicating that FeNO is valuable as a negative predictive parameter for distinguishing patients with airway hyperresponsiveness (AHR). ${ }^{12}$ Similarly, in our study, FeNO values were significantly different between patients with BHR and those without BHR, suggesting that FeNO can be used as a predictor of BHR.

FeNO values have been found to be similar between atopic and healthy individuals, ${ }^{25}$ so we did not collect atopic information on the patients in this study. In addition, smoking is associated with a reduction in FeNO levels. ${ }^{26}$ Although smoking cessation leads to an increase 
in FeNO values, ${ }^{27}$ the FeNO of ex-smokers is higher than that of healthy people who have never smoked. ${ }^{28}$ Therefore, we compared the proportion of ex-smokers between the two groups and found no significant difference between them. Considering that the number of patients with allergic rhinitis among those with BHR was higher than that among those without BHR in our study and that FeNO values are higher in individuals with allergic rhinitis, ${ }^{25}$ multivariate analysis was used to adjust for allergic rhinitis. The significant difference in FeNO between the two groups persisted after adjusting for allergic rhinitis, indicating that FeNO can be used as a predictor of BHR. ROC curve analysis showed that the AUC of FeNO in predicting BHR in patients with chronic cough was 0.854 , and the optimal cut-off value was $>31.5$ $\mathrm{ppb}$, with a sensitivity and specificity of $65.52 \%$ and 93.98\%, respectively. FeNO has low sensitivity but acceptable specificity for the diagnosis of BHR, similar to the result of a meta-analysis of FeNO for diagnosing asthma. ${ }^{29}$

Overall, the low sensitivity of FeNO limits its use as the only diagnostic parameter for BHR and asthma. However, when traditional assessment tools such as spirometry are added, FeNO improves the accuracy of diagnosis. ${ }^{12}$ Indeed, one study has shown that SAD can be predicted in asthma patients with FEV1 $\geq 80 \%$, which may help support the early diagnosis of mild asthma. ${ }^{10}$ Furthermore, MMEF can be combined with FeNO to support asthma diagnosis in patients with asthma symptoms. ${ }^{10}$ In addition, the current study revealed that MMEF in patients with BHR was much lower than that in patients without BHR. Our findings also showed that FEV1, PEF, $\mathrm{MEF}_{75}, \mathrm{MEF}_{50}$ and $\mathrm{MEF}_{25}$ in patients with BHR were much lower than those in patients without BHR and that indices that reflect more proximal airway obstruction, such as FEV1/FVC, performed less well than small airway function indicators, such as MMEF. We assume that methacholine may be deposited in the airway near the proximal end if the small airway index is high, increasing the decrease in FEV1 during methacholine inhalation, which is related to BHR. As the value of any single index in the diagnosis of BHR is not high, we examined combinations of FeNO and spirometric parameters. Multivariate logistic analysis showed that after adjusting for allergic rhinitis, the combination of FeNO and MMEF (model 2) had the strongest predictive value among the investigated combinations (AUC 0.919; sensitivity, $79.31 \%$; specificity, $92.77 \%$; $\mathrm{P}<0.001$ ); the other parameters were eliminated from the model due to their correlation with these two parameters and their low prediction accuracy. Combining FeNO and MMEF provided better predictive value than either alone.

Some studies have shown that spirometry is not sensitive for assessing $\mathrm{SAD},{ }^{30,31}$ possibly because forced expiration might alter bronchomotor tone. ${ }^{32}$ In contrast, IOS might be a useful method for detecting SAD in subjects with chronic respiratory symptoms because of its higher sensitivity. ${ }^{15}$ It seems that IOS has certain value in predicting $\mathrm{BHR}$. $\mathrm{Li}$ et al reported that among IOS parameters, AX and Fres are associated with asthma. ${ }^{15}$ Similarly, our study revealed significant differences in Fres, X5 and AX between the two groups. X5 is defined as the peripheral elastic resistance. When SAD and lung compliance decrease, the negative value will increase significantly. ${ }^{33}$ Similar to $\mathrm{X} 5$, the Fres value can reflect distal airway obstruction, ${ }^{34}$ and Fres is higher in patients with asthma. ${ }^{35} \mathrm{AX}$ is the area of reactance that reflects the elastic properties of the lung and smallairway patency. ${ }^{36,37}$ R5-R20, a parameter reflecting peripheral airway resistance, was not significantly different between the two groups, similar to the results of Kim. ${ }^{38}$ Small changes in the airway of patients who have normal airway flow might not affect the reactance in a clinically meaningful way. Considering that Fres, X5 and AX exhibited only mild to moderate diagnostic value, we combined FeNO with various IOS parameters, and multivariate logistic analysis showed that after adjusting for allergic rhinitis, the combination of FeNO and Fres (model 1) had the strongest predictive value among the combinations (AUC 0.914; sensitivity, 82.76\%; specificity, 92.77\%; $\mathrm{P}<0.001)$. We also explored the value of all parameters in the diagnosis of BHR. In the multivariate logistic analysis, the combination of FeNO, Fres and MMEF (model 3) had the strongest predictive value among the combinations (AUC 0.927; sensitivity, $79.31 \%$; specificity, 97.59\%; $\mathrm{P}<0.001)$. To examine the stability and repeatability of the three multifactor models, we established control models using 1000 bootstrapped samples, and internal validation of the three control models indicated good consistency and accuracy.

Some studies have shown that blood eosinophils, sputum eosinophils and FeNO have high diagnostic value for asthma, particularly if used in combination. ${ }^{10,39,40}$ Nevertheless, as a parameter obtained from an invasive method, eosinophils have lower diagnostic value than FeNO. $^{41,42}$ In addition, FeNO is associated with eosinophils. $^{43}$ Therefore, we conclude that FeNO is more suitable than eosinophils for predicting BHR in primary 
hospitals and that there is no need to combine FeNO with eosinophils. As the purpose of our study was to find simpler, safer or lower-cost tests that can be performed in primary hospitals to predict BHR, we did not collect blood-related indicators or sputum eosinophils.

This study has some limitations. First, it was a singlecentre study carried out in a third-class hospital in Guangzhou; hence, the results may not be representative of the entire patient population. Second, the patients in this study were enrolled from August 2018 to February 2019, so season may have affected the diagnostic value of the parameters. Third, due to the sample size, we did not conduct subgroup analyses of ex-smokers vs never-smokers. Finally, only the bootstrapping method was used for internal validation of the three models, and verification in other hospitals is needed to increase the applicability of the results.

\section{Conclusion}

To summarize, the current study suggests that in patients with chronic cough, values of IOS and spirometric parameters that reflect small-airway function are significantly lower in patients with BHR than in those without BHR. After adjusting for rhinitis, the combinations of FeNO and Fres (model 1), FeNO and MMEF (model 2), and FeNO, Fres and MMEF (model 3) all displayed a strong ability to discriminate between chronic cough patients with and without BHR. The results indicate that FeNO and IOS, FeNO and spirometry or a combination of these three parameters can be used to predict BHR in primary hospitals with an unconditional BPT.

\section{Data Sharing Statement}

The datasets used and analysed during this study are available from the corresponding author on reasonable request.

\section{Ethics and Consent Statements}

This study adheres to the principles of the Declaration of Helsinki. The protocol was approved by the Ethics Committee of Zhujiang Hospital of Southern Medical University, China (Ethical Approval no.2018-HXNK-002). Each patient has been informed about the purpose of the study and gave a consent before enrolment. Patients' privacy and personal identity information were well protected.

\section{Acknowledgments}

The study was financially supported by Guangdong Basic and Applied Basic Research Foundation (Grant no. 2020A1515010119).

\section{Disclosure}

The authors report no conflicts of interest in this work.

\section{References}

1. Canning BJ, Chang AB, Bolser DC, Smith JA, Mazzone SB, McGarvey L. Anatomy and neurophysiology of cough: chest guideline and expert panel report. Chest. 2014;146(6):1633-1648. doi:10.1378/chest.14-1481

2. Cho SH, Lin HC, Ghoshal AG, et al. Respiratory disease in the Asia-Pacific region: cough as a key symptom. Allergy Asthma Proc. 2016;37(2):131-140. doi:10.2500/aap.2016.37.3925

3. Irwin RS, Madison JM. The diagnosis and treatment of cough. $N$ Engl J Med. 2000;343(23):1715-1721. doi:10.1056/ NEJM200012073432308

4. Lai K, Chen R, Lin J, et al. A prospective, multicenter survey on causes of chronic cough in China. Chest. 2013;143(3):613-620. doi:10.1378/chest.12-0441

5. Corrao WM, Braman SS, Irwin RS. Chronic cough as the sole presenting manifestation of bronchial asthma. $N$ Engl $J$ Med. 1979;300(12):633-637. doi:10.1056/NEJM197903223001201

6. Irwin RS, Baumann MH, Bolser DC, et al. Diagnosis and management of cough executive summary: ACCP evidence-based clinical practice guidelines. Chest. 2006;129(1):1S-23S. doi:10.1378/ chest.129.1_suppl.1S

7. Achilleos A. Evidence-based evaluation and management of chronic cough. Med Clin North Am. 2016;100(5):1033-1045. doi:10.1016/j. mona.2016.04.008

8. Coates AL, Wanger J, Cockcroft DW, et al. Ers technical standard on bronchial challenge testing: general considerations and performance of methacholine challenge tests. Eur Respir J. 2017;49(5). doi:10.1183/13993003.01526-2016

9. Dweik RA, Boggs PB, Erzurum SC, et al. An official ATS clinical practice guideline: interpretation of exhaled nitric oxide levels ( $\mathrm{F}$ e NO) for clinical applications. Am J Respir Crit Care Med. 2011;184(5):602-615. doi:10.1164/rccm.9120-11ST

10. Bao W, Zhang X, Yin J, et al. Small-airway function variables in spirometry, fractional exhaled nitric oxide, and circulating eosinophils predicted airway hyperresponsiveness in patients with mild asthma. J Asthma Allergy. 2021;14:415-426. doi:10.2147/JAA.S295345

11. Hou L, Hao H, Huang G, et al. The value of small airway function parameters and fractional exhaled nitric oxide for predicting positive methacholine challenge test in asthmatics of different ages with Fev1 $>/=80 \%$ predicted. Clin Transl Allergy. 2021;1:e12007.

12. Bao W, Zhang X, Lv C, et al. The value of fractional exhaled nitric oxide and forced mid-expiratory flow as predictive markers of bronchial hyperresponsiveness in adults with chronic cough. $J$ Allergy Clin Immunol Pract. 2018;6(4):1313-1320. doi:10.1016/j. jaip.2017.09.026

13. Usmani OS. Small airways dysfunction in asthma: evaluation and management to improve asthma control. Allergy Asthma Immunol Res. 2014;6(5):376-388. doi:10.4168/aair.2014.6.5.376

14. Boeck L, Gensmer A, Nyilas S, et al. Single-breath washout tests to assess small airway disease in Copd. Chest. 2016;150(5):1091-1100. doi:10.1016/j.chest.2016.05.019

15. Li LY, Yan TS, Yang J, et al. Impulse oscillometry for detection of small airway dysfunction in subjects with chronic respiratory symptoms and preserved pulmonary function. Respir Res. 2021;22(1):68. doi:10.1186/s12931-021-01662-7

16. Konstantinos KK, Kostikas K, Kontakiotis T. Techniques for assessing small airways function: possible applications in asthma and Copd. Respir Med. 2016;119:e2-e9. doi:10.1016/j.rmed.2013.05.003

17. Lipworth BJ, Clark DJ. Effects of airway calibre on lung delivery of nebulised salbutamol. Thorax. 1997;52(12):1036-1039. doi:10.1136/ thx.52.12.1036 
18. Desiraju K, Agrawal A. Impulse oscillometry: the state-of-art for lung function testing. Lung India. 2016;4:410-416.

19. Exhaled NO. ATS/ERS recommendations for standardized procedures for the online and offline measurement of exhaled lower respiratory nitric oxide and nasal nitric oxide, 2005. Am J Respir Crit Care Med. 2005;171:912-930. doi:10.1164/rccm.200406-710ST

20. Oostveen E, MacLeod D, Lorino H, et al. The forced oscillation technique in clinical practice: methodology, recommendations and future developments. Eur Respir J. 2003;22(6):1026-1041. doi:10.1183/09031936.03.00089403

21. Miller MR, Hankinson J, Brusasco V, et al. Standardisation of spirometry. Eur Respir J. 2005;26(2):319-338. doi:10.1183/ 09031936.05.00034805

22. Di Cicco M, Peroni DG, Ragazzo V, Comberiati P. Application of exhaled nitric oxide (Feno) in pediatric asthma. Curr Opin Allergy Clin Immunol. 2021;21(2):151-158. doi:10.1097/ACI.0000000000000726

23. Chatkin JM, Ansarin K, Silkoff PE, et al. Exhaled nitric oxide as a noninvasive assessment of chronic cough. Am J Respir Crit Care Med. 1999;159(6):1810-1813. doi:10.1164/ajrccm.159.6.9809047

24. Zhang L, Liu S, Li M, Xu X. Diagnostic value of fractional exhaled nitric oxide in cough-variant asthma: an updated meta-analysis. J Asthma. 2020;57(3):335-342. doi:10.1080/02770903.2019.1568452

25. Linhares D, Jacinto T, Pereira AM, Fonseca JA. Effects of atopy and rhinitis on exhaled nitric oxide values - a systematic review. Clin Transl Allergy. 2011;1:8. doi:10.1186/2045-7022-1-8

26. Kharitonov SA, Robbins RA, Yates D, Keatings V, Barnes PJ. Acute and chronic effects of cigarette smoking on exhaled nitric oxide. Am J Respir Crit Care Med. 1995;152(2):609-612. doi:10.1164/ ajrccm.152.2.7543345

27. Robbins RA, Millatmal T, Lassi K, Rennard S, Daughton D. Smoking cessation is associated with an increase in exhaled nitric oxide. Chest. 1997;112(2):313-318. doi:10.1378/chest.112.2.313

28. Malinovschi A, Janson C, Holmkvist T, Norback D, Merilainen P, Hogman M. Effect of smoking on exhaled nitric oxide and flow-independent nitric oxide exchange parameters. Eur Respir J. 2006;28(2):339-345. doi:10.1183/09031936.06.00113705

29. Sano H, Tomita K, Sano A, et al. Accuracy of objective tests for diagnosing adult asthma in symptomatic patients: a systematic literature review and hierarchical bayesian latent-class meta-analysis. Allergol Int. 2019;68(2):191-198. doi:10.1016/j.alit.2018.08.013

30. Skloot G, Goldman M, Fischler D, et al. Respiratory symptoms and physiologic assessment of ironworkers at the world trade center disaster site. Chest. 2004;125(4):1248-1255. doi:10.1378/ chest.125.4.1248

31. Cottini M, Licini A, Lombardi C, Berti A. Clinical characterization and predictors of ios-defined small-airway dysfunction in asthma. J Allergy Clin Immunol Pract. 2020;8(3):997-1004. doi:10.1016/j. jaip.2019.10.040
32. Burns GP, Gibson GJ. A novel hypothesis to explain the bronchconstrictor effect of deep inspiration in asthma. Thorax. 2002;57 (2):116-119. doi:10.1136/thorax.57.2.116

33. Bickel S, Popler J, Lesnick B, Eid N. Impulse oscillometry: interpretation and practical applications. Chest. 2014;146(3):841-847. doi:10.1378/chest.13-1875

34. Galant SP, Komarow HD, Shin HW, Siddiqui S, Lipworth BJ. The case for impulse oscillometry in the management of asthma in children and adults. Ann Allergy Asthma Immunol. 2017;118(6):664-671. doi:10.1016/j.anai.2017.04.009

35. Cavalcanti JV, Lopes AJ, Jansen JM, Melo PL. Detection of changes in respiratory mechanics due to increasing degrees of airway obstruction in asthma by the forced oscillation technique. Respir Med. 2006;100(12):2207-2219. doi:10.1016/j.rmed.2006.03.009

36. Bednarek M, Grabicki M, Piorunek T, Batura-Gabryel H. Current place of impulse oscillometry in the assessment of pulmonary diseases. Respir Med. 2020;170:105952. doi:10.1016/j. rmed.2020.105952

37. Brashier B, Salvi S. Measuring lung function using sound waves: role of the forced oscillation technique and impulse oscillometry system. Breathe (Sheff). 2015;11(1):57-65. doi:10.1183/20734735.020514

38. Kim SR, Park KH, Son NH, et al. Application of impulse oscillometry in adult asthmatic patients with preserved lung function. Allergy Asthma Immunol Res. 2020;12(5):832-843. doi:10.4168/ aair.2020.12.5.832

39. Beretta C, Rifflart C, Evrard G, Jamart J, Thimpont J, Vandenplas O. Assessment of eosinophilic airway inflammation as a contribution to the diagnosis of occupational asthma. Allergy. 2018;73(1):206-213. doi:10.1111/all.13265

40. Giovannelli J, Cherot-Kornobis N, Hulo S, et al. Both exhaled nitric oxide and blood eosinophil count were associated with mild allergic asthma only in non-smokers. Clin Exp Allergy. 2016;46(4):543-554 doi:10.1111/cea.12669

41. Korevaar DA, Westerhof GA, Wang J, et al. Diagnostic accuracy of minimally invasive markers for detection of airway eosinophilia in asthma: a systematic review and meta-analysis. Lancet Respir Med. 2015;3(4):290-300. doi:10.1016/S2213-2600(15)00050-8

42. Fortuna AM, Feixas T, Gonzalez M, Casan P. Diagnostic utility of inflammatory biomarkers in asthma: exhaled nitric oxide and induced sputum eosinophil count. Respir Med. 2007;101(11):2416-2421. doi:10.1016/j.rmed.2007.05.019

43. Jeppegaard M, Veidal S, Sverrild A, Backer V, Porsbjerg C. Validation of ATS clinical practice guideline cut-points for feno in asthma. Respir Med. 2018;144:22-29. doi:10.1016/j. rmed.2018.09.014

\section{Publish your work in this journal}

The Journal of Asthma and Allergy is an international, peer-reviewed open-access journal publishing original research, reports, editorials and commentaries on the following topics: Asthma; Pulmonary physiology; Asthma related clinical health; Clinical immunology and the immunological basis of disease; Pharmacological interventions and

Submit your manuscript here: https://www.dovepress.com/journal-of-asthma-and-allergy-journal new therapies. The manuscript management system is completely online and includes a very quick and fair peer-review system, which is all easy to use. Visit http://www.dovepress.com/testimonials.php to read real quotes from published authors. 